\title{
Effects of topiramate on cognitive function
}

\author{
P J Thompson, S A Baxendale, J S Duncan, J W A S Sander
}

\begin{abstract}
Objective-To explore the impact of topiramate on tests of intellect and other cognitive processes.

Methods-This was a retrospective study. The neuropsychological test scores of 18 patients obtained before and after the introduction of treatment with topiramate (median dose $300 \mathrm{mg}$ ) were compared with changes in test performance of 18 patients who had undergone repeat neuropsychological assessments at the same time intervals. Complaints of cognitive decline precipitated referral for reassessment in five cases in the topiramate treated group. The groups were matched for age and intellectual level at the time of the first assessment. Patients were assessed using the WAIS-R, tests of verbal and non-verbal memory, language, and perceptual processing. A subgroup of patients underwent a brief reassessment after the withdrawal or substantial reduction of topiramate.
\end{abstract}

Results-Repeat assessments in those taking topiramate were associated with a significant deterioration in many domains, which were not seen in the comparison group. The greatest changes were for verbal IQ, verbal fluency, and verbal learning $(\mathbf{p}<0.001)$. Improvements in verbal fluency $(p<0.05)$, verbal learning $(p<0.01)$, and digit span $(p<0.001)$ were recorded in those patients who had topiramate withdrawn or reduced.

Conclusions-In our patient group topiramate had a negative impact on cognition which was consistent with subjective complaints of patients. Tests requiring verbal processing seemed especially sensitive to the drug. A decline in verbal intellect (VIQ), a measure which has been considered by some to be insensitive to antiepileptic drug effects, was particularly striking. Caution is warranted in the interpretation of the findings due to methodological limitations of the study design. Further investigation of mediating factors such as serum concentrations, comedication, and other potential risk factors, however, is needed to enable appropriate targeting of treatment with this effective antiepileptic agent. (F Neurol Neurosurg Psychiatry 2000;69:636-641)

Keywords: epilepsy; topiramate; intellect; memory; seizures

Correspondence to:

Dr Pam Thompson

PamT@epilepsyrise.co.uk

Received 20 January 2000 and in revised form

8 June 2000

Accepted 6 July 2000 management of intractable seizures. ${ }^{1-3}$ More recent studies have shown high levels of adverse effects. ${ }^{4}$ Cognitive complaints are prominent among the untoward effects reported and include impaired concentration and memory, slowed thinking, and word finding difficulties. ${ }^{256}$ There have been few investigations, however, measuring cognitive changes more systematically, with the use of neuropsychological tests.

Existing studies suggest undesirable cognitive changes which corroborate subjective complaints. Burton and Harden ${ }^{7}$ assessed 10 adult patients with epilepsy at weekly intervals for up to 13 weeks with one measure of cognitive performance, a digit span test. The dosage of topiramate was determined by assessed clinical need and varied over the study period, averaging $100 \mathrm{mg}$ to $355 \mathrm{mg}$. No significant drug effect was seen in the group as a whole. For four patients, however, there was a significant inverse correlation between topiramate dosage and test performance, with higher doses being associated with lower scores. The authors took their findings to indicate individual differences in the sensitivity of attentional processes to the drug.

Martin et $a l^{\beta}$ assessed the cognitive impact of up to $5.7 \mathrm{mg} / \mathrm{kg}$ daily of topiramate in healthy volunteers who remained on the drug for 4 weeks. Performance was assessed in the acute phase of treatment and again at 2 and 4 weeks. Volunteers were given up to $5.7 \mathrm{mg} / \mathrm{kg}$ daily. Other subjects were assessed at the same time intervals on gabapentin and lamotrogine treatment. Impaired cognitive functioning was recorded in the topiramate group in the acute phase and at 4 weeks, which was not apparent in the other two groups. Statistically significant declines were recorded on measures of attention, verbal fluency, and verbal memory.

We had noted cognitive difficulties in several patients treated with topiramate that were consistent with subjective complaints described by other authors. In the first few patients who underwent repeated neuropsychological assessments we found a decline in functioning that included a significant fall on a test of verbal intelligence; a measure that previously has been considered relatively insensitive to antiepileptic drug effects. ${ }^{9}$ As intellectual decline may occur in some patients with intractable epilepsy, we were anxious not to wrongly attribute the cognitive change to a medication which had improved seizure control in several patients. The aims of this study were to explore further whether cognitive changes in our patients were indeed a consequence of topiramate and to assess whether certain cognitive processes, in particular measures involving verbal processing, were selectively affected. 
Table 1 Patient details

\begin{tabular}{lll}
\hline & Topiramate & No topiramate \\
\hline Men/women & $14 / 4$ & $12 / 6$ \\
Age (y) (median (range)) & $31(17-49)$ & $28(18-50)$ \\
Interval between sessions (months) (median (range)) & $36(5-59)$ & $36(3-60)$ \\
Age at onset of epilepsy (y) (median (range)) & $9(1-38)$ & $10(1-25)$ \\
Epilepsy type: & 14 & 15 \\
$\quad$ Partial & 4 & 3 \\
$\quad$ Generalised & & \\
\hline
\end{tabular}

\section{Subjects and methods}

METHODS

The patients studied had intractable epilepsy and were attending a tertiary referral epilepsy assessment unit.

\section{SUBJECTS}

Group 1

Eighteen consecutive referrals taking topiramate at the time of the assessment were included if a neuropsychological assessment had been undertaken before the introduction of this drug. Patients had been taking topiramate for a median of 11 months with a range of 3-37 months. All patients were receiving at least one other antiepileptic drug. Topiramate dosage ranged from $125 \mathrm{mg}$ to $600 \mathrm{mg}$ with a median of $300 \mathrm{mg}$. For five cases complaints of cognitive deterioration were a major factor precipitating a further assessment. Of the remaining 13 patients, seven had been referred for presurgical investigations and six because of suboptimal seizure control or the need for diagnositic clarification.

A subgroup of eight patients was available for a brief reassessment a minimum of 10 days after the discontinuation or a substantial reduction of the drug. The topiramate dose of these patients ranged from $175 \mathrm{mg}$ to $600 \mathrm{mg}$. At the reassessment seven patients were no longer on the drug and one patient had the dosage reduced from $600 \mathrm{mg}$ to $175 \mathrm{mg}$.
Group 2

Patients were recruited from the same source if two neuropsychological assessments had been undertaken at about the same time interval as in group 1.

Patients were excluded from both groups if a significant event known to have an impact on cognitive functioning had occurred between the assessments-for example, surgery and episode(s) of status epilepticus. Patients who had known neurodegenerative conditions were excluded. No recent drug changes had taken place in either group.

There was no significant difference between the groups for age, level of intellectual functioning at the initial testing session, and the interval between testing sessions. Tables 1 and 2 provide demographic, seizure, and treatment related details.

NEUROPSYCHOLOGICAL TESTING

The neuropsychological tests were not selected to be sensitive to drug effects. The measures formed part of the routine neuropsychological assessment of our clinical service. There was some variability in the tests given to individual patients and therefore we selected only those measures that had been administered in both assessments. These are described briefly below.

\section{Intellect}

Wechsler adult intelligence scale, revised ${ }^{10}$-Seven subtests of the WAIS-R were available for analysis; digit span, vocabulary, similarities, and arithmetic from the verbal scale; and picture arrangement, picture completion, and block design from the performance scale. Verbal subtests were analysed as a quotient and also as individual subtests to enable more detailed analysis of verbal processing. The performance subtests were analyzed only as the overall prorated quotient.

Table 2 Seizure and antiepileptic drug (AED) details

\begin{tabular}{|c|c|c|c|c|}
\hline & \multicolumn{2}{|c|}{ Topiramate group } & \multicolumn{2}{|c|}{ Comparison group } \\
\hline & $\begin{array}{l}\text { Session } 1 \text { (no } \\
\text { TPM) Median } \\
\text { (range) }\end{array}$ & $\begin{array}{l}\text { Session } 2 \text { (on } \\
\text { TPM) Median } \\
\text { (range) }\end{array}$ & $\begin{array}{l}\text { Session 1 } \\
\text { Median } \\
\text { (range) }\end{array}$ & $\begin{array}{l}\text { Session } 2 \\
\text { Median } \\
\text { (range) }\end{array}$ \\
\hline \multicolumn{5}{|l|}{ Seizure frequency (3 months pretesting): } \\
\hline Complex partial & $18(6-120)$ & $9(3-84)^{\star}$ & $16.5(6-36)$ & $14(0-72)$ \\
\hline Generalised tonic & $3(1-18)$ & $1(0-9)^{\star}$ & $3(1-30)$ & $2.5(0-36)$ \\
\hline Atonic & 6 & 0 & 12 & 12 \\
\hline \multicolumn{5}{|l|}{ AEDs: } \\
\hline Median number taken & 2.3 & 2.6 & 2.0 & 2.3 \\
\hline CBZ (median dose, No on drug and range) & $\begin{array}{l}1300(14) \\
400-1800\end{array}$ & $\begin{array}{l}1600(14) \\
400-2200\end{array}$ & $\begin{array}{l}1000(9) \\
800-2000\end{array}$ & $\begin{array}{l}1200(13) \\
600-1800\end{array}$ \\
\hline VPA & $\begin{array}{l}2000(6) \\
1100-3000\end{array}$ & $\begin{array}{l}1500(7) \\
500-2000\end{array}$ & $\begin{array}{l}1400(11) \\
500-2000\end{array}$ & $\begin{array}{l}1800(6) \\
1200-3000\end{array}$ \\
\hline PHT & $\begin{array}{l}400(4) \\
300-375\end{array}$ & $300(1)$ & $\begin{array}{l}425(6) \\
250-475\end{array}$ & $\begin{array}{l}400(5) \\
200-450\end{array}$ \\
\hline LTG & $\begin{array}{l}300(4) \\
100-600\end{array}$ & None & $\begin{array}{l}425(4) \\
300-500\end{array}$ & $\begin{array}{l}400(5) \\
200-450\end{array}$ \\
\hline CLB & $\begin{array}{l}10(3) \\
10-30\end{array}$ & $10(3)$ & $10(2)$ & $\begin{array}{l}10(5) \\
5-10\end{array}$ \\
\hline CLZ & $3(1)$ & $2(1)$ & $2(1)$ & $\begin{array}{l}9(2) \\
3-12\end{array}$ \\
\hline GBP & $\begin{array}{l}2100(4) \\
900-2500\end{array}$ & None & $3600(1)$ & $1200(1)$ \\
\hline GVG & $2000(3)$ & $2000(1)$ & & \\
\hline Other & & $4000(1)$ & $250(1)$ & $250(1)$ \\
\hline
\end{tabular}

${ }^{\star} \mathrm{p}<0.01$.

$\mathrm{CBZ}=$ Carbamazepine; $\mathrm{VPA}=$ sodium valproate; $\mathrm{PHT}=$ phenytoin; $\mathrm{LTG}=$ lamotrigine; $\mathrm{CLB}=$ clobazam; $\mathrm{CLZ}=$ clonazepam; $\mathrm{GBP}=$ gapapentin; GVG=vigabatrin; LT=levetiracetam; PMD=primidone. 
Verbal memory

The story recall and list learning subtests from the adult memory and information processing battery (AMIPB) were administered. ${ }^{11}$ In the recall task the patient is read a passage and asked to recall as many ideas as possible from a maximum of 60 both immediately after presentation (immediate story recall) and 30 minutes later (delayed story recall) The story percentage retained score (delayed recall/immediate recall) is also calculated. In the list learning task the patient is read a list of 15 common words and asked to recall as many as possible. The list is then read a further four times with the patient recalling as many words as possible after each trial. The total number of words recalled during the five trials is recorded (list A 1-5). Then a second list of 15 words is presented. The patient is required to recall as many as possible from the second list (list B) and then from the original list without a further presentation (list A 6).

\section{Language}

The McKenna graded naming test provided one measure of expressive language function. The subject is required to name 30 line drawings of objects of increasing difficulty. The score derived is the total number correct. ${ }^{12}$ Data were also available from a measure of verbal fluency. In the test adopted the subject is required to produce as many words beginning with the letter ' $\mathrm{s}$ ' in one minute and then to name as many animals beginning with any letter of the alphabet also in 60 seconds. The two totals achieved were analysed individually.

The de Renzi token test (shortened version ) provided a measure of verbal comprehension. The subject is required to manoeuvre coloured shapes by command. There are 15 commands of increasing verbal complexity. The score is the total number correct. ${ }^{13}$

Spatial memory

Data were available from the figure recall and design learning subtests from the adult memory and information processing battery. In the first the subject is required to copy a complex figure and produce a version from memory, both immediately and then after a 30 minute delay. In the learning paradigm the subject is shown a simple geometric design for 10 seconds. The stimulus is removed and the subject is required to produce a copy. Five learning trials are given in total and then a new design is shown and presented for one trial; the subject is required to reproduce the original design.

Visual perception

The subject is shown 20 letters of the alphabet which have been degraded by $70 \%$. The subject must identify each letter from the incomplete stimulus. The score is the total number of letters correctly identified. ${ }^{14}$

SEIZURES

For all patients there was documentation in the case notes and from patient diaries on seizure control to enable an estimate to be made of frequency over the 3 month period before each testing session. A record was made for complex partial seizures, generalised tonic-clonic seizures, and atonic seizures. Estimates were not always available for myoclonic jerks and simple partial seizures and for this reason no figures are provided.

\section{ANTIEPILEPTIC DRUGS}

The type of medication and dosage at the time of each testing session were recorded (table 2).

\section{STATISTICAL ANALYSIS}

For all test measures a higher score indicated better performance. Change scores were evaluated for each test and subtest by subtracting the first test score from the second, a positive score representing an improvement and a negative score a deterioration. Independent sample $t$ tests were used to assess for group differences in change in scores.

Paired sample $t$ tests were performed on the test-retest scores of the eight patients in the withdrawal group.

Further correlational analyses were undertaken to explore whether there was any relation between topiramate dosage and the degree of change on the cognitive tests.

Wilcoxon $t$ tests were employed to assess whether significant changes in seizure frequency occurred between the sessions for the two patient groups.

\section{Results}

The analysis showed a decline in functioning in session 2 compared with session 1 for the topiramate group compared with the nontopiramate treated group (figure and table 3). The most significant differences in change of scores between the groups were recorded for word fluency, list learning, and verbal IQ $(p<0.001)$ with the topiramate group showing a decline in performance and the comparison group an improvement from the first to the second session. Fluency for the letter ' $s$ ' decreased by nearly $50 \%$ in the topiramate group compared with a $35 \%$ improvement in the comparison group. Analysis of the individual verbal subtests of the WAIS-R showed that the negative change was significant for two of the four subtests administered; digit span $(\mathrm{p}<0.004)$ and arithmetic $(\mathrm{p}<0.0005)$. Effects were smaller for performance IQ, de Renzi token test, and list recall $(\mathrm{p}<0.01)$ and for figure recall and story recall $(\mathrm{p}<0.05)$.No significant differences were found for the other measures.

Patients who underwent topiramate withdrawal or reduction all produced better scores after this drug change on all the tests readministered (table 4 : digit span $\mathrm{p}<0.001$; list learning $\mathrm{p}<0.01$; and fluency for ' $\mathrm{s}$ ' $\mathrm{p}<0.025$ and for animals $\mathrm{p}<0.01$ )

No significant correlations were found between individual topiramate dose and the magnitude of the change in test scores between the sessions. 


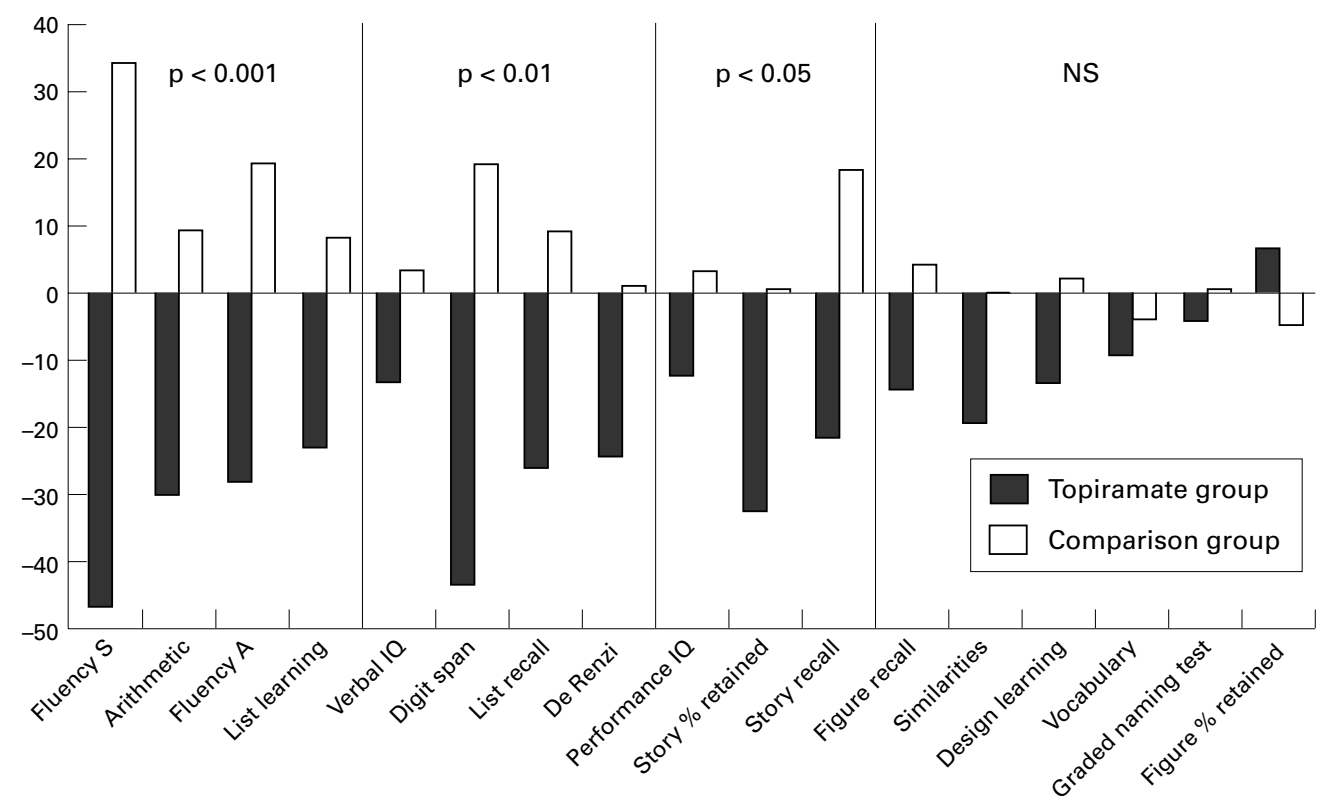

Mean \% change in score between the first and second assessment on each task.

\section{SEIZURES}

A statistically significant reduction in seizures was recorded for the topiramate treated group for both generalised tonic-clonic $(z=-2.68$; $\mathrm{p}<0.007)$ and complex partial seizures $(z$ $=-2.67 ; \mathrm{p}<0.008$, table 2$)$. No patient experienced a deterioration in seizure control when treated with topiramate. For generalised tonicclonic seizures the change in frequency ranged from no change in one patient, to no attacks during the 3 month period in six cases. The median reduction in complex partial seizures was $25 \%$ ranging from no change to $89 \%$ reduction. There were no statistically significant changes in seizure frequency in the comparison group.

Table 3 Test scores on the cognitive measures of the two patient groups in the two sessions

\begin{tabular}{|c|c|c|c|c|c|}
\hline \multirow[b]{2}{*}{ Cognitive tests } & \multirow[b]{2}{*}{$n$} & \multicolumn{2}{|c|}{ Topiramate group } & \multicolumn{2}{|c|}{ Comparison group } \\
\hline & & $\begin{array}{l}\text { Session one } \\
\text { mean (SD) }\end{array}$ & $\begin{array}{l}\text { On TPM } \\
\text { Session two } \\
\text { mean (SD) }\end{array}$ & $\begin{array}{l}\text { Session one } \\
\text { mean (SD) }\end{array}$ & $\begin{array}{l}\text { Session two } \\
\text { mean (SD) }\end{array}$ \\
\hline Verbal IQ & 18 & $93.5(9.8)$ & $81.0(11.2)$ & $91.2(8.7)$ & $93.6(10.0)^{\star \star \star}$ \\
\hline Digit span & 18 & $9.3(3.0)$ & $5.6(3.3)$ & $9.4(3.0)$ & $9.5(1.8)^{\star \star}$ \\
\hline Vocabulary & 18 & $7.9(7.1)$ & $7.0(2.4)$ & $7.9(2.4)$ & $8.3(2.6)$ \\
\hline Arithmetic & 18 & $8.8(2.9)$ & $5.8(2.3)$ & $8.9(2.9)$ & $8.8(2.5)^{\star \star \star}$ \\
\hline Similarities & 18 & $9.1(1.9)$ & $7.2(2.3)$ & $9.1(1.9)$ & $9.3(2.5)$ \\
\hline Performance IQ & 18 & $98.7(12.4)$ & $86.7(16.7)$ & $95.4(14.6)$ & $97.8(16.0)^{\star \star}$ \\
\hline \multicolumn{6}{|l|}{ Story recall: } \\
\hline Immediate & 17 & $21.9(12.5)$ & $14.7(8.7)$ & $29.6(12.4)$ & $30.5(10.9)^{\star}$ \\
\hline$\%$ Retained & 17 & $69.2(22.8)$ & $49.6(34.1)$ & $92.5(12.0)$ & $91.0(14.8)^{\star \star}$ \\
\hline \multicolumn{6}{|l|}{ List learning: } \\
\hline Lists $1-5$ & 18 & $44.2(10.1)$ & $34.1(14.2)$ & $45.0(8.8)$ & $48.3(9.5)^{\star \star \star}$ \\
\hline List 6 & 18 & $9.1(4.3)$ & $6.1(3.3)$ & $9.8(2.6)$ & $10.4(2.6)^{\star \star}$ \\
\hline List B & 18 & $4.8(2.1)$ & $4.8(1.9)$ & $4.9(1.6)$ & $5.2(2.5)$ \\
\hline Graded naming test & 18 & $15.2(6.8)$ & $13.6(7.5)$ & $16.7(7.0)$ & $16.2(7.0)$ \\
\hline De Renzi token test & 15 & $13.8(1.3)$ & $10.6(3.9)$ & $14.0(1.1)$ & $14.1(1.0)^{\star \star}$ \\
\hline Verbal fluency 's' & 18 & $13.4(5.5)$ & $7.1(4.5)$ & $11.8(2.7)$ & $15.2(3.4)^{\star \star \star}$ \\
\hline Animals & 18 & $15.7(5.8)$ & $10.6(3.9)$ & $17.5(4.7)$ & $20.0(4.6)^{\star \star \star}$ \\
\hline \multicolumn{6}{|l|}{ Figure recall: } \\
\hline Immediate & 15 & $70.6(18.9)$ & $57.2(21.8)$ & $73.2(16.2)$ & $75.5(18.0)$ \\
\hline$\%$ Retained & 15 & $89.7(10.9)$ & $94.1(10.7)$ & $95.9(7.7)$ & $90.3(24.9)$ \\
\hline \multicolumn{6}{|l|}{ Design learning: } \\
\hline Designs $1-5$ & 16 & $33.7(8.8)$ & $28.3(9.2)$ & $35.0(5.6)$ & $35.6(8.5)$ \\
\hline Design 6 & 16 & $6.6(2.4)$ & $5.3(2.9)$ & $7.5(2.3)$ & $7.7(2.3)$ \\
\hline Design B & 16 & $4.1(2.2)$ & $5.0(2.4)$ & $5.7(1.9)$ & $6.3(2.3)$ \\
\hline Fragmented letters & 16 & $18.5(1.4)$ & $17.6(2.6)$ & $17.9(1.3)$ & 18. $(1 . .5)$ \\
\hline
\end{tabular}

${ }^{\star} \mathrm{p}<0.05 ;{ }^{\star \star} \mathrm{p}<0.01 ;{ }^{\star \star \star} \mathrm{p}<0.001$.
Table 4 Test scores of patients before, during and following withdrawal $(n=7)$ or reduction $(n=1)$ of topiramate

\begin{tabular}{lccc}
\hline Cognitive tests & $\begin{array}{l}\text { Pre-TPM } \\
\text { Mean (SD) }\end{array}$ & $\begin{array}{l}\text { On TPM } \\
\text { Mean (SD) }\end{array}$ & $\begin{array}{l}\text { TPM } \\
\text { Mean }(S D)\end{array}$ \\
\hline Digit span & $8.6(1.8)$ & $6.0(3.8)$ & $8.4(3.1)^{\star \star \star}$ \\
List learning: & & & \\
$\quad$ Lists 1-5 & $39.9(6.1)$ & $33.5(13.6)$ & $42.6(7.9)^{\star \star}$ \\
$\quad$ List 6 & $7.4(1.9)$ & $5.0(3.2)$ & $7.5(2.5)^{\star \star}$ \\
Verbal fluency 's' & $8.9(2.4)$ & $6.1(3.6)$ & $10.0(4.6)^{\star \star}$ \\
$\quad$ Animals & $13.4(2.8)$ & $9.8(2.9)$ & $14.4(3.6)^{\star \star}$ \\
\hline
\end{tabular}

${ }^{\star} \mathrm{p}<0.05 ;{ }^{\star \star} \mathrm{p}<0.01 ;{ }^{\star \star \star} \mathrm{p}<0.001$

OTHER DRUGS

The groups varied in the drugs taken on the two testing sessions (table 2). The topiramate group were by definition all taking the drug in the second session. At this second session four were no longer taking gabapentin and four were no longer taking lamotrogine. Three fewer patients were taking phenytoin and two fewer vigabatrin. Sodium valproate and clonazepam had been withdrawn from one patient and levetiracetam had been added to one patient's drug regimen.

In the comparison group five patients were no longer taking sodium valproate in the second session and there was one less taking phenytoin. Four more were taking carbamazepine, three more clobazam, one more lamotrogine, and one more clonazepam.

\section{Discussion}

Topiramate treatment was associated with impairments on tests of cognitive functioning, which were not seen in patients who were not taking this drug and assessed on two occasions at similar intervals. There was a tendency to improvement in test scores from session 1 to session 2 in the second group. The changes did not seem likely to be confounded by seizure control as the patients treated with topiramate experienced fewer seizures in the 3 months before the second assessment session. All 
patients had been taking the drug for a minimum of 3 months and so the cognitive changes cannot be attributed to an acute effect expected to diminish over time, nor could they be a consequence of too rapid introduction of the drug. Neither had any recent change in dose taken place. Improvements seen in patients reassessed after topiramate had been withdrawn or reduced provides further support that the drug had been having a negative impact on cognition in our sample. Practice effects, however, cannot be ruled out as contributing to the improved scores as the testretest interval was short. We failed, however, to find any significant dose effects, unlike Burton and Harden. ${ }^{7}$ Our sample size was small but no trends were seen. We, however, could only compare dosages in different patients and had no data on varying dosages in the same patient, which would have been a more sensitive design.

Tests requiring verbal output were particularly vulnerable to topiramate treatment. Reduced verbal fluency was a particularly striking finding and one which accords with reports of the impact of topiramate treatment in healthy volunteers. ${ }^{8}$ Impaired verbal fluency is also in keeping with subjective complaints by patients and families, of word finding difficulties. The significant changes in verbal IQ recorded were surprising as such measures have been considered by some to be insensitive to antiepileptic drug effects. The change in verbal IQ was attributable to alterations in the scores on the arithmetic and digit span subtests, which suggests that short term memory may be especially vulnerable to topiramate. By contrast, on tests of non-verbal learning and recall and perceptual analysis, which are cognitively demanding, the changes on the drug were much less marked.

Our findings are in keeping with those recently described by Sziklas et al. ${ }^{15}$ These authors reported improvements in digit span, language comprehension, and fluency 10 to 14 days after the reduction of topiramate. A recent randomised clinical trial, however, has reported less marked cognitive effects of topiramate given as an add on treatment, in comparison with sodium valproate. ${ }^{16}$ The maximum dose used in this study was $200 \mathrm{mg}$, which contrasts with our median dose of $300 \mathrm{mg}$ and this may be one reason for the difference in the size of the cognitive effects between the studies. Furthermore, our patient group was biased towards those experiencing negative effects. In a randomised trial cognitive effects will be diluted if only a subgroup of patients develop such adverse changes.

This study has considerable methodological limitations in not being a prospective randomised controlled trial. It was retrospective, observational, and biased toward patients with intractable epilepsy and our findings must therefore be interpreted with caution. Further, cognitive problems precipitated referral for some cases. Patients were on various drugs and it is possible that certain combinations placed them at risk for cognitive problems. Other drug dosages were not constant through the study, but a review of the results does not suggest that changes to other medications are a tenable explanation of the findings. Our numbers were too small to permit meaningful analysis of drug combinations and we cannot comment on the possible impact of topiramate monotherapy from this study.

The findings from this study have clinical implications. In recent years reviews of the literature on antiepileptic drugs have concluded that adverse effects are small ${ }^{17}$ or have emphasised positive psychotropic effects. ${ }^{18}$ In such a climate there is a risk that the negative impact of drugs may be underestimated and declines in functioning on topiramate misinterpreted as deterioration secondary to intractable epilepsy. ${ }^{19}$ The magnitude of the cognitive changes reported here are sufficient to have an impact on everyday life and to reduce a person's efficiency at school, at work, and in social settings. Furthermore, we have recent experience of patients undergoing evaluation for right temporal lobe surgery being wrongly deemed poor candidates due to impaired performance on tests of verbal memory and other verbal tasks, which subsequently improved when topiramate was withdrawn.

Topiramate is clearly an effective antiepileptic agent but some patients seem susceptible to cognitive decline. Further prospective investigations of mediating factors such as serum concentrations, comedication, and other potential risk factors are needed to enable appropriate targeting of treatment. In the meantime, we recommend that patients and their families and acquaintances are given explicit advice on potential adverse cognitive effects in the same way that candidates for epilepsy surgery are counselled on possible cognitive sequelae. We also suggest that patients are assessed neuropsychologically to monitor changes before and after treatment.

We are grateful to the National Society for Epilepsy for support. The Epilepsy Research Group has received research and travel grants from the manufacturers of many antiepileptic drugs, including topiramate.

1 Tassarini CA, Michelucci R, Chauvel P, et al. Double-blind placebo controlled trial of topiramate (600 mg daily) for the treatment of refractory epilepsy. Epilepsia 1996;37:763-

2 Privitera M, Fincham R, Penry J, et al. Topiramate placebo controlled dose: ranging trial in refractory partial epilepsy using 600,800 , and $1000 \mathrm{mg}$ daily dosages. Neurology 1996;46:1678-83.

3 Elterman RD,Glauser TA, Wyllie E, et al. A doubleblind,randomized trial of topiramate as adjunctive therapy for partial-onset seizures in children. Topiramate YP Study Group. Neurology 1999;52:1338-44.

4 Kellert MW, Smith DF, Stockton PA, et al. Topiramate in clinical practice: first years postlicensing experience in a specialist epilepsy clinic. F Neurol Neurosurg Psychiatry 1999;66:759-63.

5 Crawford P. An audit of topiramate use in a general neurology clinic. Seizure 1998;7:207-11.

6 Jones MW. Topiramate: safety and tolerability. Can $\mathcal{F}$ Neurol Sci 1998;25:S13-15.

7 Burton LA, Harden C. Effect of topiramate on attention. Epilepsy Res 1997;27:29-32.

8 Martin R, Kuzniecky R, Ho S, et al. Cognitive effects of topiramate, gabapentin and lamotrogine in healthy young adults. Neurology 1999;52:321-7.

9 Thompson PJ, Trimble MR. Neuropsychological aspects of epilepsy. In: Grant I, Adams K, eds. Neuropsychological assessment of neuropsychiatric disorders. New York :Oxford assessment of neuropsychiatric disor.
University Press, 1996:263-88.

10 Wechsler D. Wechsler adult intelligence scale, revised. San Antonio. TX: The Psychological Corporation, 1981. 
11 Coughlan A, Hollows S. Adult memory and information processing battery. Leeds, UK: St James Hospital, processing.

12 McKenna P, Warrington E. The graded naming test. Windsor, UK: NFER Nelson, 1983

13 Coughlan AK, Warrington EK. Word comprehension and word retrieval in patients with localised brain lesions. Brain 1978;101:63-185.

14 Warrington EK, James M. The visual object and space perception battery. Bury St Edmunds: Thames Valley Test Company, 1991.

15 Sziklas VG, Montour-Proulx I, Andermann F, et al. Cognitive effects of topiramate therapy in patients with intractable partial epilepsy. Epilepsia 1999;40(suppl7):56.
16 Aldenkamp AP, Baker G, Mulder OG, et al. A randomized clinical study comparing the cognitive effects of topiramate versus valproate in a first line add on design. Epilepsia 1999;40(suppl 7):83-4.

17 Vermeulen J, Aldenkamp AP. Cognitive side-effects of chronic antiepileptic drug treatment: a review of 25 years research. Epilepsy Res 1995;22:65-95.

18 Meador KJ. The cognitive effects of new AEDs. Neurologist 1998;4:S35-9.

19 Jokeit H, Ebner A. Long term effects of refractory temporal lobe epilepsy on cognitive abilities: a cross sectional study. F Neurol Neurosurg Psychiatry 1999;67:4450

William Stewart Halsted (1852-1922)

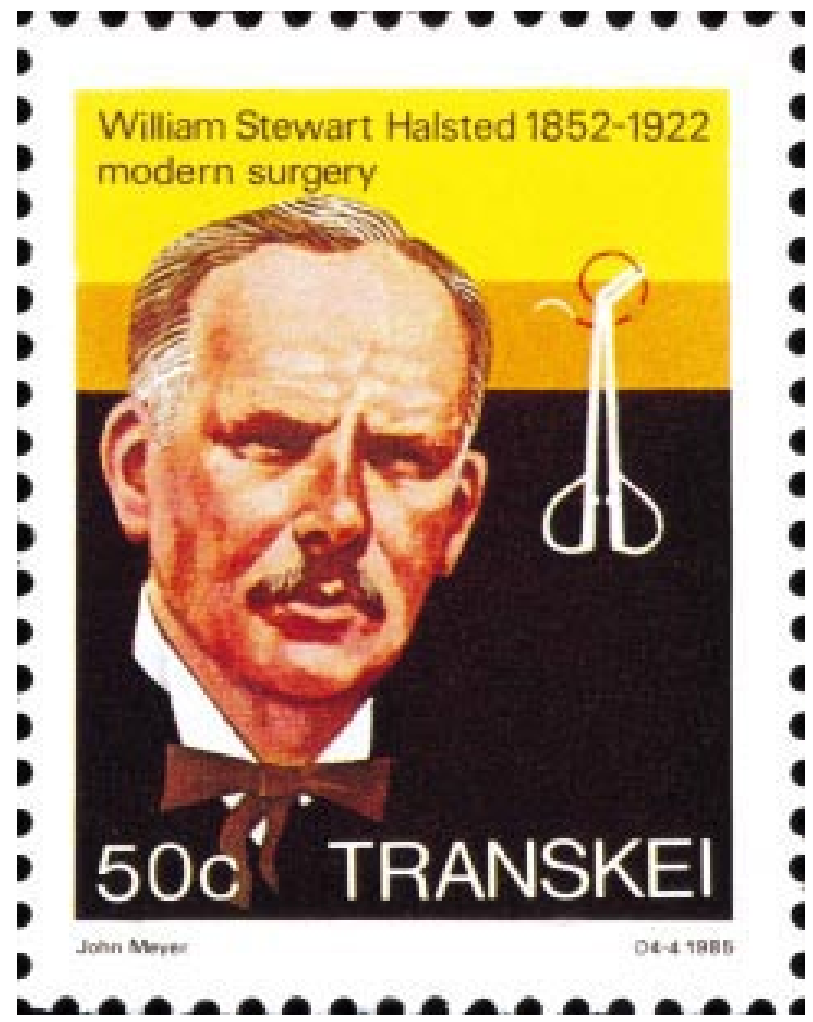

Among surgeons who decisively influenced concepts and the technical procedures of surgery was WS Halsted. Halsted became the first professor of surgery at John Hopkins Medical School at Baltimore in 1892. He, Osler, Kelly, and Welch, were four major figures who made John Hopkins famous at the time. At one time one of his assistants was Cushing.

After graduating in 1877 he spent 2 years as a postgraduate student at the Universities of Vienna, Leipzig, and Würzburg. When he returned to the United States he worked as a surgeon in several New York hospitals before a growing addiction to cocaine forced him to leave in search of a cure. Carl Koller in 1884 demonstrated the effectiveness of cocaine as a local anaesthetic. Halsted recognised the importance of this work. Experimentation with cocaine led to his addiction. Three of his fellow experimenters also became addicted and all three died. In 1885 he showed that local anaesthesia could be produced by infiltration of cocaine around appropriate nerves. The drug that had been introduced into medicine by Sigmund Freud, also in 1884, rapidly became a valuable anaesthetic for minor surgery.

One of his greatest contributions was the lead he took in aseptic surgery. In 1889 Halsted introduced thin rubber gloves into operating theatres. This followed his arranging with the Goodyear Rubber Company to make gloves for Caroline Hampton, his future wife, whose hands were allergic to the antiseptic used.

Halsted is depicted on a stamp issued by Transkei in 1985 (Stanley Gibbons 179, Scott 112). 